\title{
Teaching English through Play: Then and Now
}

\author{
Stephen J. Senderoff \\ University of Florida PA-S1, Gainesville, USA
}

\begin{abstract}
In this present age of intercultural communication and social media, learning a second language has become of paramount importance to many students. English is perhaps the most demanded foreign language, and many teachers have found that one of the best ways to teach English is through the use of "play." While play has been a component of teaching English as a foreign language for many years, teachers have had to adapt their use of play to keep up with the technological and cultural changes taking place in educational institutions throughout the world. This paper aims to examine how the use of "play" in teaching English as a foreign language has both developed and changed over the last 35-40 years, through a review of educational literature. Examples of the types of "play" studied include drama and digital play, and it is found that different types of play provide students with different arenas in which to learn English. A more thorough look at technological play and second language learning would complement the findings of this paper.
\end{abstract}

Index Terms - play, language, education, second language learning, second language acquisition

\section{INTRODUCTION}

In order to successfully show how the use of "play" in second language teaching has developed and changed over the last 35-40 years, it is important to first establish a definition of what the word "play" means in a linguistic context. This is not an easy task to accomplish, as Chance (1979) points out in the first line of his book Learning Through Play, "Play is like love: everybody knows what it is but nobody can define it." Alderman (1974) defines play as activities done solely for fun, enjoyment, and personal-satisfaction (p. 23-26). Catharine Garvey (1977) describes play as being pleasurable, spontaneous, inherently unproductive (Intrinsically motivated), and actively engaged with by the player (p. 4). Deci and Ryan (1985) believe that play is heavily involved in the curiosity-based, intrinsically motivated behavior that promotes children's cognitive development and learning (p. 122). Spodek and Saracho (1988) define play as being distinct from work (p. 11).

An activity is considered play, if it is not work. In other words, it is not the activity itself, but the reasons for that activity that determines whether it is play or work. According to this definition, any activity done for its own sake would be classified as play, while any activity done for an external reason or reward, such as a salary or pay, would be considered work. Spodek and Saracho use the example of professional versus amateur athletes. When a group of children get together to play a light game of football in the park, it is play. However, when Joe Montana, a professional football player, steps onto the field on Sunday afternoon, it is most definitely work, due to the seriousness and external motivation of the game. The activity didn't change, but the reason for the activity did. Sutton-Smith (2003) uses a 1985 Oxford English Dictionary definition of "fun" to define play: "to make a fool of someone or something." He goes on to say that one way to define play is, "behavioral parody of emotional vulnerability," because play makes fun of primary emotions like anger, fear, and narcissism. "It makes fun of it all" (p.13). In the Forward of Gaye Gronlund's book Developmentally Appropriate Play, Dr. Ellen Frede (2010) speaks on how there is a difference between play that is effective and play that doesn't provide students with opportunities to make choices, solve problems, work cooperatively with others, or develop rich language (p. xii). She then explains how children often view play as anything that they "don't have to do" (p. xiii).

This then begs the question, how can play (something that is intrinsically motivated and not "fun" unless done for its own sake) be used to teach students a second language (giving the play an extrinsic motivation and making it still something that the students "have to do")? It would seem that forcing students to partake in language play would defeat the purpose of play, but only if the students were not interested in the extrinsic motivation for the activity, that is, learning a second language. However if the students are interested in learning a second language, the acquisition of said language then becomes an intrinsic motivation for the play that is occurring, meaning that the children are playing a game or participating in play which has the purpose of bettering their language skills, so they become interested in the play because it is giving them a better grasp on the second language. Cook (2000) backs up this statement, “...for both the first and the second language learner, language play is much more than merely a potential means. As a widespread, highly valued use of language, of social and cognitive importance, it is also an end. Knowing a language and being able to function in communities which use that language, entails being able to understand and produce play with it, making this ability a necessary part of advanced proficiency" (p. 150). Cook describes language play as involving the patterning of linguistic form, the creation of alternative realities, and the social use of both of these for intimacy and conflict (p. 5). He also describes language play as enjoyable, consisting of fun and amusement, but apparently unnecessary to the dayto-day business of survival (p. 36). This type of language play he defines as semantic, or playing with the meaning of 
words and combining them together to create fiction. He also speaks on formal language play: playing with the sound, rhyme, repetition, or grammatical structures of language to produce parallelisms or patterns.

Now that the definition of "play" has been established as any activity that has intrinsic motivation, is enjoyable, is "not work," and is partaken in voluntarily; it is possible to examine the role of play in second language acquisition. While the studies of play and second language learning have been heavily researched and written about for at least the last 50 years, the study of how play actually influences language learning seems to have become important only recently. Play boosts language learning by providing increased input and by increasing child engagement (Weisberg et. al, 2013).

Four characteristics of play link play and language skills. The first characteristic of play is that it often enlists symbolic thinking. For example, in play, props serve as symbols for real objects, like banana to telephone. This relationship between a prop and the object it represents resembles the relationship of a word to its referent. The second characteristic of play is that the social interaction inherent in play feeds into language development. This is because the taking on of different roles and negotiating different points of social play appear to encourage children to practice more advanced linguistic forms than they would use in other interactions. The third characteristic of play that links play and language skills is that the amount of language input available in play contributes to language development. Finally, the fourth characteristic of play is that when children are in control of an interaction (play) they are engaged. They speak about and listen to what interests them. This convergence seems to apply especially in the case of adult interaction. Guided play, which incorporates elements of adult scaffolding in service of a learning goal, but which primarily follows a child's lead and builds on his/her interests, provides a particularly effective language-learning environment. Indeed, this definition of play emphasizes the need for the child to lead the activity.

A Study by Julia Sevy-Biloon (2017) found that students showed more interest, had increased motivation and advanced more quickly in English language learning when games were incorporated into the class on a regular basis. Even though many of these students did not have intrinsic motivation for learning English (they thought it wouldn't help them in their future or that it was too difficult), games intrinsically motivated the learners to internalize the previous language introduced in the class. The study also found that competition is important because it can challenge students, and when students are challenged more motivation is created, making students more responsive, engaged and enthusiastic about participating and learning. Students, wanting to succeed in games, began to internalize and practice parts of speech and vocabulary. Using games seems to be a more effective, enjoyable method than forcing the students to study for a test. This teaching style seems to work best when students need some intrinsic motivation.

\section{DRAMA}

The first type of "play" used in teaching English as a foreign language that will be discussed in this paper is drama. From a very young age, children love using their imaginations and pretending that things are not quite as they seem. They jump from couch to bed, imagining that the floor is lava and would burn them alive if they were to accidently touch it. They pretend to be cowboys, princesses, and superheroes drinking tea together. While it may not seem like it at first, they are participating in the very old human tradition of drama and acting. After reading Drama Techniques in Language Learning by Maley and Duff from 1978, and then numerous articles from the last 10 years, It appears that while the majority of techniques involved in teaching a second language through the use of dramatic activities have stayed the same, there has been a shift in the main focus (from language focused and trying to reinforce the textbook, to culturally and interpersonally focused) of many of these activities.

It is important to first define "drama" in a classroom context before diving into the history of its use in foreign language classrooms. Drama is defined by Maley and Duff (1978) as "activities which give the student an opportunity to use his/her own personality in creating the material on which part of the language class is to be based" (p. 1). This definition is similar to Weisberg's belief that play should be a child led activity, which should only be moderated and directed by the teacher. Maley and Duff view drama as a means to motivate the students, to train them in emotional and interpersonal intelligence, and to teach them language in a more natural way. In an email interview conducted with Professor Sidney R. Homan of the University of Florida (2017), Professor Homan stated his belief that people are performing the art of drama whenever they interact with others. Every time someone interacts with another human being, they are fashioning a role for themselves, a persona, whether it be "as a friend or as a waiter." Homan goes on to say that drama is about the experience of the play for the actors and the audience; it is the meaning of the art that should be emphasized through the medium of acting. This is similar to Maley and Duff's view on drama, that it "reverses the learning process, that is, by beginning with meaning and moving to language from there" (p. 7). Gill (2013) emphasizes the communicative aspects of drama, describing it as an art form that allows students to talk freely and experiment with their second language.

Drama is used in many ways and for many reasons in the classroom. One strategy described by Maley and Duff that drama uses is encouraging students to view language from a different perspective than they ever have before. Drama pushes students to get a behind-the-scenes view of the words and actions which they are most likely to use in the language, giving them a better understanding of the underlying patterns present behind all languages. Drama has the students focus on the functions of language, "such as persuading, agreeing, and accepting." This requires an awareness of the total situation in which language is being used, which is considerably richer than the mere physical setting. The authors then provide a description of the "total situation:" Setting, is important because physical surroundings are often 
incidental to what is being said. Role and Status plays a part in language teaching because "if we ignore roles, we teach language in a vacuum." The listeners and the roles that are being played in the setting matter to what is said and how it is spoken. Mood, Attitude and Feeling influence grammatical form; as these are all situations that can be practiced through imagining and acting. Shared knowledge is what the speaker and the listener already know (p. 4-7).

One example of how teaching English as a foreign language through drama has changed over the last 40 years is in memorization. According to Maley and Duff, "Words, other people's words, which have been mechanically memorized, can be ashes in the speaker's mouth." (p. 1). They believe that having students memorize lines to perform them in front of an audience later takes away from the intrinsic value of the now, by giving the dramatic activities extrinsic motivation (p.1). Gill (2013), on the other hand, believes that memorizing lines for rehearsals and ultimately performances allows the student to internalize the structure and meaning of the lines, giving them the ability to reproduce them automatically when required. Gill argues for rote-learning, as long as the teacher is helping the students to make connections. Shafka (2012) believes that performing rehearsed and memorized drama is beneficial for students learning English, as long as the students start out by learning modern drama without archaic English diction. This view of using performance and memorization starkly contrasts Maley and Duff's view that dramatic activities are not part of the preparation for some great final performance (p.1).

\section{A. Drama and Emotional Intelligence}

"Acting is the art which is common to all of us (everybody can act - more or less!) ... also an art which can help to build human beings into something better and more understanding than they are by nature - to build then into sensitive creatures able to feel the sorrow and joys of others as their own."

-Sybil Thorndike in Foreword for Peter Slade's book Child Drama (1954).

One area in which the use of drama has stayed mostly the same over the last 40 years has been the area of training both students and teachers in "Emotional Intelligence." According to Baklashova et al. (2016), emotional intelligence (EI) is defined as the potential of a person to perceive and accurately express one's own and others' emotions; their ability to support thinking processes through the use of emotions; their qualities such as self-awareness and motivation; and their ability to understand, express, and control emotions. EI can then be used as a tool to teach students to become more self-aware, and to better understand their own motives and driving forces. This greater level of self-awareness will allow students to be more honest with themselves in regard to their "strengths and weaknesses," making them more efficient at improving their second language skills, because they will know exactly which areas to focus on.

Maley and Duff speak on the use of drama to develop a child's EI. "Language is not purely an intellectual matter. ... The intellect rarely functions without an element of emotion" (1978, p. 2) Drama focuses on the inherent meaning in every lingual interaction the students experience; they are not worrying about language for the sake of language alone, but they are learning language by focusing on the meaning of the interactions and the underlying social cues that take place. Many authors from the last decade agree that teaching English through drama also strengthens a student's EI. Gill (2013) describes how drama allows students to focus more on what they are saying and the meaning behind it, than if it is grammatically or structurally "accurate." This moves the student closer to conversational fluency than just focusing on the structural and grammatical elements of language, because it strengthens their ability to pick up on the underlying meaning in the second language. Shafka (2012) states that "good literature [drama] deals with some aspects of the human condition and attempts to come to some understanding of life, either symbolically or metaphorically, and can contribute to the emotional development of a child."

While the view that drama can increase a student's EI has not changed much over the years, many recent authors believe that this social and cultural aspect of teaching English through drama is becoming even more important than the lingual aspect itself. Heikkinen (2016) believes that because the world is becoming more and more complex socially, technologically and politically, socially critical thinking is more important now than ever. While Maley and Duff emphasized the importance of a student's social and interpersonal growth, they did not seem to attribute as much importance to the EI aspect of learning a language as modern authors. In this modern age of social media, being able to connect with people from other cultures and "put yourselves in their shoes," has become even more crucial.

\section{B. Drama and Interdisciplinary Learning}

One of the main concepts discussed in the literature which can help a second language instructor provide the best possible education for his or her students is the idea of using an interdisciplinary approach to teaching. Before describing how drama utilizes this style of teaching, it is important to first provide a brief definition. According to Psoinos (2012), "Interdisciplinary language teaching focuses on content, and thus imparts knowledge through the use of the target language." Much of the criticism involving second language instruction is centered around the idea that most students finish the class having only practiced skills that will help them pass a test. This is often due to the fact that most teachers focus solely on teaching students the vocabulary and grammar of a new language for the sake of language alone, without focusing enough on the content involved in the process. A more holistic approach to language teaching and learning involving a broader range of disciplines, such as geography, history, and the sciences, would create more interest in the students and more efficient language acquisition. Schleppegrell (2018) explains in her article that language teachers need to collaborate with subject-area teachers because of the subject-specific ways that language is 
used. This interaction and teamwork helps learners bridge the gap between their language-learning classes and the other classes they take each day, providing them with more diverse exposure to English and extra avenues through which to practice their second language.

According to Maley and Duff, drama utilizes many different disciplines in order to teach English to students. They describe Drama as the "naughty child" who climbs over the high, exclusive walls set by teachers of other subjects. Drama takes life as the starting point for learning, not language. "Drama may involve music, history, painting, mathematics, skiing, photography, cooking - anything. It does not respect subject barriers" (p. 10). Professor Homan (2017) also backs up this view of drama as being an interdisciplinary teaching style, "I've used drama... in a variety of courses by colleagues at the University of Florida, where I tried to complement a fellow teacher and his or her subject with dramatizing that subject." Homan believes that drama can enhance and inform the lives of those who partake in it, no matter if the participant is a doctor trying to improve their "bedside manner," or a businessperson wanting to grow in their ability to interact with clients. It would also seem that learning about other subjects and disciplines would be even more important in the modern day, due to the fact that people are no longer expected to pick a single career out of high school and college and stick with that career until the day they retire.

Another reason why teaching a foreign language through the use of many disciplines with drama is very successful is because many young students are accustomed to one teacher giving them lessons in a broad range of subjects. In most primary schools throughout the world, students receive all of their instruction in the differing subjects from the same teacher during a school day. However, students usually will have to receive their foreign language instruction from a native speaker of that language, especially in places where both languages are so rarely spoken by a single educator. Rather than making the foreign language teacher a forty-five-minute part of the day, schools could implement interdisciplinary learning and have the foreign language teacher teach the basics of other subjects in that language, thus giving students more context for vocabulary and grammar.

\section{TECHNOLOGY}

Nothing has changed education more in the last 35-40 years than the incredible advances made in the field of technology. If you needed to find information 40 years ago, you would be directed to a large stack of dusty encyclopedias in a bookshelf and told to "look it up." Today, almost everyone has a smartphone in their pocket with access to countless search engines. Supercomputers used to take up a whole room; now they fit in the palm of your hand. This surge of technology has greatly affected how human beings go about "playing." Children used to have to come up with games entirely on their own and with only things in the "real world" to use as "props." This meant that the imagination was key in play (remember the floor as lava example from earlier?). With the influx of technology, children are thrust into virtual reality and hyper-realistic graphics, taking imagination almost entirely out of the picture. A child can now turn on their TV and spend hours living the life of a digital professional athlete, all from the comfort of their air-conditioned room. While some virtual reality and role-playing games are starting to bring back the element of imagination in second language learning through play, technology still has a long way to go to match the imagination of a child.

\section{A. Past Trends}

In his book, Computers and English Language Learning, John Higgins (1995) speaks on computers when they were first beginning to be used heavily in education and English language teaching. In the introduction, Higgins states that language learning has little to do with machines (technology and computers in general), but a great deal to do with play. Higgins values CALL (computer-assisted language learning) because it allows for more language exploration and richer play than had ever been possible before (p. v). Computers contribute to learning being intrinsically motivated (playful) because students have more fun being on the computer and are likely to use it more than a book with exercises (p. 92). This is why even children with ADHD can sit in front of a screen for hours and hours on end without needing anything but the computer and its games to keep their attention. CALL changes the role of the teacher from "knower" to mediator and advisor whose job is to lead the child through activities on the computer (p. 7). This is similar to children learning English through the use of drama, in that in both instances the teachers are allowing the child to take control of his/her own learning.

While Higgins clearly thinks highly of using computers in language learning, it is important to note that a major theme of his book is that computers are inferior to humans. For example, Higgins frequently describes computers as "stupid," functioning best as "slaves" to humans, and as "unintelligent" (p. 5,18,36,37). He then states that "many things that humans do effortlessly are done at best laboriously by machines" (p. 32). This view of computers as being lowly machines with the sole purpose of serving humans is in stark contrast to the common view of today's researchers: that computers and technology have unlimited potential and extreme intelligence (Pesudo and Renau, 2016; Forsythe 2013; Figueroa Flores 2015). According to Higgins, computers seem to be more about copying what teachers and humans are already doing in education, rather than using virtual reality or technology to come up with something new (p. 33). Most of the games on computers described in his book seem to just be quicker and neater versions of games that could just as well be played with pencil and paper (p. 5).

\section{B. Current Trends}


Technology has taken the educational world by storm and is now being heavily used to teach English in a foreign language setting. Forsythe (2013) describes how technology allows instant and free contact between people in countries around the globe through social media and video conferencing (such as Facebook and Skype). This means that a teacher in Japan can set up a video conference with a teacher in England, allowing the two classes to interact with each other and share their different cultures and languages. For instance, the games described by Sevy-Biloon (2017) such as charades and monopoly could be played between Japanese and American students over a Skype or Zoom session. Forsythe (2013) goes on to list websites such as Quizlet and Livemocha which allow students to practice English through the use of flash cards and timed activities, creating a competition in which the goal is to beat their old times and the times of other students. Another interesting website Forsythe describes in his article is Second Life, in which students can create an avatar and interact with foreign speakers in a virtual world. This is very similar to learning English through drama, in that it provides a role and setting to the conversation.

One popular trend in language teaching today is that of Gamification, or the use of game mechanics in a typically non-game related context, such as second language learning (Figueroa Flores 2015). Figueroa Flores states that the main objective of using Gamification is to "increase participation and motivate users through the use of game elements such as points, leaderboards, and immediate feedback." These game elements empower and engage the "user" (student) by giving them processes to work through and tasks to complete. Gamification is especially useful in teaching the "digital natives" (students who grew up blogging, texting, and gaming), because receiving information through technology is what they are most accustomed to. A good example of gamification in language learning is the popular smartphone application Duolingo. Duolingo gives users practice with speaking, listening, grammar and vocabulary in many different foreign languages. The app gives immediate feedback and even offers daily reminders with notifications. One criticism of Duolingo is that many of the sentences a user practices with are random generations and hardly ever take place in a real-world context. However, it is a fun app that has already helped many people progress towards learning a second language. Gamification motivates users intrinsically by creating in students the desire to master the game and providing students with autonomy and a sense of belonging. In addition to this, there are also extrinsic rewards such as levels, points, and badges to be obtained. While pure play is intrinsically motivated, the extrinsic motivation does create an even better learning environment for students learning a second language through gamification.

Another interesting technological trend in using play to teach English as a foreign language is 3D virtual reality (Molka-Danielsen et al. 2016). Advocates for the use of virtual technology in education and language learning claim that $3 \mathrm{D}$ environments engage the user; "facilitating comprehension, interaction, and collaboration by the means of situating learning materials in an immersive context." If a teacher can combine virtual reality with pedagogical tools such as role playing and interdisciplinary learning, students will greatly benefit from these 3D environments. MolkaDanielsen provides an example of this sort of environment by analyzing a study in which Austrian and Norwegian students interacted in a virtual village mystery game using the English language. The researcher found that the students' oral proficiency in English greatly increased from playing the game. There were many reasons for the benefits received from the 3D game, such as the fact that students pursued shared academic goals to complete the task of finding out why the inhabitants of the virtual village had disappeared. Also, students were intrinsically motivated to solve the mystery, and because the only way to do this was by speaking in English to one another, they received a great amount of practice through these exchanges. Finally, students participated in play because they were personally interested in the game and the mystery, crime, and private investigation that took place in the virtual environment. Another point that MolkaDanielsen makes in regard to the benefit of virtual reality is that participating in activities such as these cuts down on the test anxiety most students suffer from when forced to answer questions in a typical quiz or test setting.

\section{Drawbacks of Technology in Education}

Many researchers have expressed their concern with how technology is affecting play and education. Klorer (2009) believes that communication through technology and the synthetic world in which technological play operates is the reason why children are not developing sound interpersonal skills. She also argues that staring at a screen takes away from the "relational aspect of eye-to-eye gazing." Perhaps reasons like this are why some teachers are still resistant to implementing technology into their teaching activities, despite the mainstream love of technology (Renau and Pesudo, 2016). Even Figueroa Flores (2015) admits that while gamification is clearly beneficial to the world of second language learning, it does promote introversion and shyness in its users. After Nguyen and Le's study (2020) looked at how students in Vietnam responded to language learning from a textbook, many of the students commented that they would learn better working with other members of the class, rather than by themselves in a book. This lack of interpersonal collaboration in language acquisition then occurs not only in technology but also from the classic textbook approach. Technology is clearly beneficial to education; however, it is important that educators keep in mind the human aspect of learning a language.

\section{CONCLUSION}

The use of play in teaching English as a foreign language has changed and developed over the last 35 to 40 years. The dramatic arts teach students to focus on the meaning being conveyed, rather than just the grammatical and 
structural elements of language. While not much has changed in the pedagogy of drama, teachers nowadays place a very heavy focus on developing interpersonal skills and learning about other cultures due to social media and one-world connectedness. The evolution of technology has also had a very large impact on second language instruction. When computers became a part of the English teacher's repertoire they were often viewed as simple machines that were only useful for replicating what an everyday teacher could do (Higgins 1995). In the present day however, functions such as gamification and virtual reality have completely changed how instructors go about teaching foreign languages. Research also indicates that while technology is likely to continue to be a large part of foreign language instruction, it can also be detrimental in some ways to the development of a student's social skills. Hopefully, the information in this paper is useful for any teacher looking to utilize "play" in their foreign language class.

The research in this paper raises further questions. With all the new technology and video game systems becoming integrated into teaching foreign languages, will there ever be a time when language classes are taught solely with virtual reality? What is the next step in technology and language teaching? With language evolving every year, will Shakespeare ever be completely obsolete in classrooms? While some research already addresses these questions, further research will still be needed as education changes each and every year.

\section{REFERENCES}

[1] Alderman, R. B. (1974). Psychological Behavior in Sport. Philadelphia, PA: W. B. Saunders, 23-26.

[2] Baklashova, T. A and Galishnikova, E. M and Khafizova, L. A. (2016). "Prerequisites for Emotional Intelligence Formation in Second Language Learning and Career Choice.” International Journal of Environmental and Science Education, 11(5), 923930.

[3] Chance, Paul. (1979). Learning Through Play. New Brunswick, NJ: Johnson \& Johnson Baby Products Company.

[4] Cook, G. (2000). Language play, Language learning. Oxford: Oxford University Press.

[5] Deci, E.L and R. M. Ryan. (1985). Intrinsic Motivation and Self-Determination in Human Behaviour. New York: Plenum, 122.

[6] Figueroa F and Francisco, J. (2015). "Using Gamification to Enhance Second Language Learning." Digital Education Review, (27), 32-54.

[7] Forsythe, E. (2013). Autonomous Language Learning with Technology. JALT CALL Journal, 9(3), 329-337.

[8] Garvey, C. (1977). Play. Cambridge, MA: Harvard University Press.

[9] Gill, C. (2013). Oral Communication in ESL through Improvisations, Playwriting and Rehearsals. Advances in Language and Literary Studies, 4(1), 34-41.

[10] Gronlund, G. Forward by Ellen Frede. (2010). Developmentally Appropriate Play: Guiding Young Children to a Higher Level. St. Paul, MN: Redleaf Press.

[11] Heikkinen, H. M. (2016). Drama and Citizenship--Devised Drama for Education. Journal of Social Science Education, 15(4), 32-39.

[12] Higgins, J. (1995). Computers and English Language Learning. New York: Ablex Publishing Corporation.

[13] Homan, S. R. (2017). Email Interview with author, University of Florida. 7 April 2017.

[14] Klorer, G. P. (2009). The Effects of Technological Overload on Children: An Art Therapist's Perspective. Art Therapy: Journal of the American Art Therapy Association, 26(2), 80-82.

[15] Le, D. T. K and Nguyen, C. T. (2020). Communicative Language Teaching: Do Tasks and Activities in School Textbooks Facilitate Learners' Development of Communicative Competence. Journal of Language Teaching and Research 11(5), 688700 .

[16] Maley, A and Duff, A. (1978). Drama Techniques in Language Learning. Cambridge University Press.

[17] Molka-Danielsen, J and Hadjistassou, S. and Messl-Egghart, G. (2016). Investigating the Affective Learning in a 3D Virtual Learning Environment: The Case Study of the Chatterdale Mystery. Research publishing.net, Paper presented at the EUROCALL 2016 Conference (23rd, Limassol, Cyprus, Aug 24-27, 2016).

[18] Pesudo, M and Renau, M. L. (2016). Analysis of the implementation of a WebQuest for learning English in a secondary school in Spain. International Journal of Education and Development using Information and Communication Technology (IJEDICT), 12(2), 26-49.

[19] Psoinos, D. I. (2012). Do Our Coursebooks Live up to the Challenges of Today? Adopting an Interdisciplinary Approach to TEFL. Reading Matrix: An International Online Journal, 12(2), 177-180.

[20] Schleppegrell, M. J. (2018). The knowledge base for language teaching: What is the English to be taught as content? Language Teaching Research, 24(1), 17-27.

[21] Sevy-Biloon, J. (2017). Different Reasons to Play Games in an English Language Class. Journal of Education and Training Studies, 5(1), 84-93.

[22] Shakfa, M. D. A. (2012). Difficulties Students Face in Understanding Drama in English Literature at the Islamic University of Gaza (IUG). English Language Teaching, 5(9), 95-103.

[23] Spodek, B and Saracho, O. N. (1988). The Challenge of Educational Play. Play as a Medium for Learning and Development. Ed. by Doris Bergen. Portsmouth, NH: Heinemann Educational Books, Inc, 11.

[24] Sutton-Smith, B. (2003). Play as a Parody of Emotional Vulnerability. Play and Educational Theory and Practice. Ed. by Donald E. Lytle. Westport, CT: Praeger Publishers.

[25] Weisberg, D, S and Zosh, J. M and Hirsh-Pasek, K. and Golinkoff, R. M. (2013). Talking It Up: Play, Language Development, and the Role of Adult Support. American Journal of Play, 6(1), 39-54. 


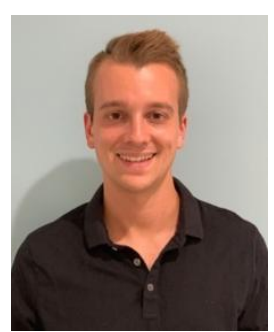

Stephen J. Senderoff was born in New Haven, Connecticut in 1996. He received his BA in English from the University of Florida in 2019, where he specialized in creative writing and poetry. Over the past year he has worked as a nurse tech at UF Health Shands Hospital in Gainesville, Florida, as well as a private caregiver. In July of 2020 he began attending the University of Florida School of Physician Assistant Studies. 